\title{
Clinical effect of locking compression plate via posterolateral approach in the treatment of distal femoral fractures: a new approach
}

\author{
Wenzhao Xing ${ }^{1}$, Wei Lin², Jia Dai ${ }^{3}$, Zhigang Kong ${ }^{1}$, Yanfeng Wang ${ }^{1}$, Lei Sun ${ }^{1}$, Zhiguo Zhang ${ }^{1}$ and Liang Sun ${ }^{1 *}$
}

\begin{abstract}
Background: Distal femur fractures are difficult to manage, and the selection of implant approach for internal fixation remains controversial. This study explores the clinical outcome of treating distal femoral fractures with a locking compression plate using a posteriolateral novel approach.

Methods: Twenty patients with distal femoral fractures were included in our study, and all patients underwent fixation of the fracture using a locking compression plate through a posterolateral approach. The postoperative fracture healing time, complications, and functional recovery were observed and recorded. The joint function was categorized according to the Kolmert functional criteria.

Results: All patients were followed up for an average of 12 months, and all incisions healed by first intention. Among the all patients, 19 patients achieved fracture healing 3 to 4 months after surgery. The remaining 1 patient with distal femoral $C_{3}$ comminuted fracture achieved partial fracture healing 15 months after surgery, and bone grafting was needed. All knees can reach the state of straightening, and the postoperative excellent rate was $90 \%$. Among them, 8 patients had maximal flexion of more than $120^{\circ}, 10$ patients had flexion between $90^{\circ}$ and $120^{\circ}$, and 2 other patients had flexion of $70^{\circ}$ and $40^{\circ}$.
\end{abstract}

Conclusions: Fixation of the fracture using a locking compression plate through a posterolateral approach seemed to be an acceptable surgical option for treatment of distal femoral fractures.

Keywords: Femoral fracture, Internal fixation, Posterolateral approach, Locking compression plate

\section{Background}

Fractures of the distal femur are severe injuries that present many clinical challenges to the orthopedic surgeon $[1,2]$. These fractures are often unstable and comminuted and tend to occur in elderly or multiply injured patients [2]. For long, gold standard treatment modality for fixation of the distal femur fractures was angle blade plate (ABP), compression screw, and side plate devices such as dynamic condylar screw (DCS). Insertion of blade plates is technically demanding; DCS and $\mathrm{ABP}$ require removal of a large amount of bone for

\footnotetext{
*Correspondence: sunlianghebei@163.com

'Department of Orthopaedics, The Third Hospital of Hebei Medical

University, No. 139 Ziqiang Road, Shijiazhuang 050051, China

Full list of author information is available at the end of the article
}

insertion; condylar buttress plates (CBP) lack the stability of fixed angle devices and are prone to varus collapse or screw failure [3, 4]. Retrograde intramedullary nails (IMNs) were not sufficient for stabilizing fragmented articular fractures $[5,6]$. Nowadays, anatomically contoured locking plates and locking screws are being used more commonly for surgical fixation during distal femur fractures.

Current generation of distal femoral locking compression plates is pre-contoured based on the average bony anatomy of the adult population and they form a fixed angled construct. The pull-out strength of locking screws is higher than the conventional screws and is particularly useful in osteoporotic bones. These plates are designed to apply in minimally invasive fashion to preserve local biology and avoid fracture healing and infection problems $[7,8]$. 
Various treatment methods have been used for distal femoral fractures. They include direct-indirect reduction, open-minimal invasive approaches, and open-slipped techniques. Condylar plates, dynamic condylar screws, condylar buttress plates, anterograde nails, retrograde nails, internal fixators, and external fixators play a more and more important role in the treatment of distal femur fractures [9]. Good fixation outcomes depend on bone quality, fracture complexity, and surgical techniques. Reddy and Chary [10] used anterolateral parapatellar approach or lateral approach for the treatment of distal femoral fractures. Anteriormiddle approach [11] and a new anterolateral approach [12] of distal femur for treatment of distal femoral fractures were reported previously. However, no reports have been reported on the treatment of distal femoral fractures by a locking compression plate via a posterolateral approach so far.

Based on the study above, our study was designed to explore the superiority of the posterior lateral approach for a locking compression plate in the treatment of distal femoral fractures.

\section{Methods}

\section{Patients}

We retrospectively collected the clinical data of patients with distal femoral fractures who underwent application of a locking compression plate through a posterolateral approach from March 2010 to May 2014. Ethical approval was given by the Medical Ethics Committee of the Third Hospital of Hebei Medical University. Written informed consent was obtained from all study participants.

Inclusion criteria were as follows: (1) type A and type $\mathrm{C}$ distal femoral fractures and (2) patients older than 18 years of age.

Exclusion criteria include as follows: (1) type B distal femoral fractures; (2) patients with poor physical conditions; (3) patients contraindicated for surgery or anesthesia; (4) patients who had wound infection prior to internal fixation; (5) patients with chronic osteomyelitis or malignant tumors; and (6) patients with concomitant neurovascular injury.

\section{Preoperative preparation}

Radiological evaluation included anteroposterior and lateral X-rays of the femur with knee, along with a pelvic $\mathrm{X}$-ray to rule out proximal fractures. Computed tomography (CT) scans (Fig. 1a, b) were done to better delineate the fracture anatomy and to allow detailed subgroup classification. Chest X-ray, ECG, and laboratory tests were performed to evaluate the patients' surgical tolerance. Patients with contraindications to surgery were excluded. All fractures were classified according to AO/OTA, and an operative proposal was made on the basis of pre-operation examination results.

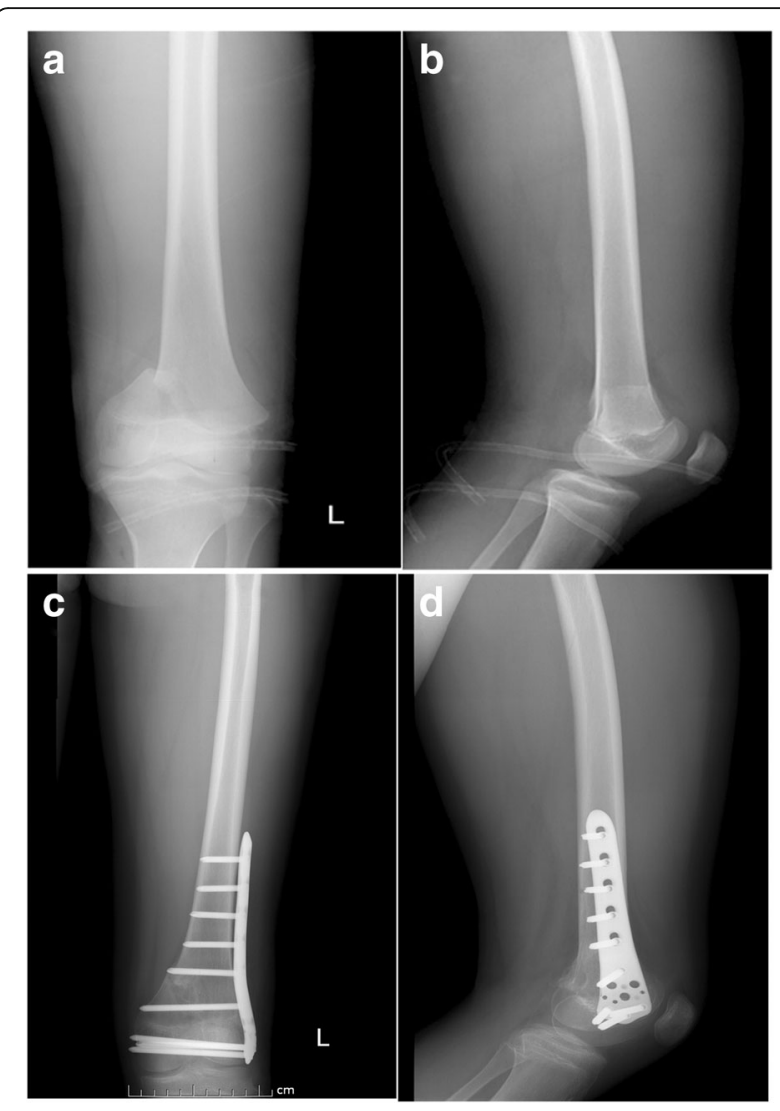

Fig. 1 Preoperative and immediate postoperative images of $X$-rays. $\mathbf{a}, \mathbf{b}$ Preoperative $X$-rays anteroposterior and lateral views of knee joint showing distal femur fracture. $\mathbf{c}$, $\mathbf{d}$ Immediate postoperative anteroposterior and lateral $\mathbf{X}$-rays showing fracture consolidation

\section{Surgical procedure}

After spinal anesthesia, the electric tourniquet was fixed on the suffered limb. A lateral incision of the distal femur extending to the anterior lateral of the knee was obtained. The skin, subcutaneous tissue, deep fascia, and knee joint capsule were cut successively, and the vastus lateralis muscle was revealed (Fig. 2a). The femoral lateral muscle was bluntly separated along its trailing edge. To fully reveal the distal femoral fracture, the periosteum was cut open and stripped. Attention should be paid to protect the integrity of the suprapatellar bursa during the above step (Fig. 2b). For distal femoral fracture type C, the condylar fractures and the anatomical structure of the articular surface of the femoral condyle was restored firstly. For distal femoral fracture type A, temporary fixation was performed by using Kirschner wire, and then hollow screw fixation was conducted after obtaining a satisfactory position. After confirming the fixation, the fracture of the femoral condyle was reset; line of force and the length of the affected limb were restored. Bone graft in stage I was performed for patients with supracondylar comminuted fracture. After the reduction of the fracture, 


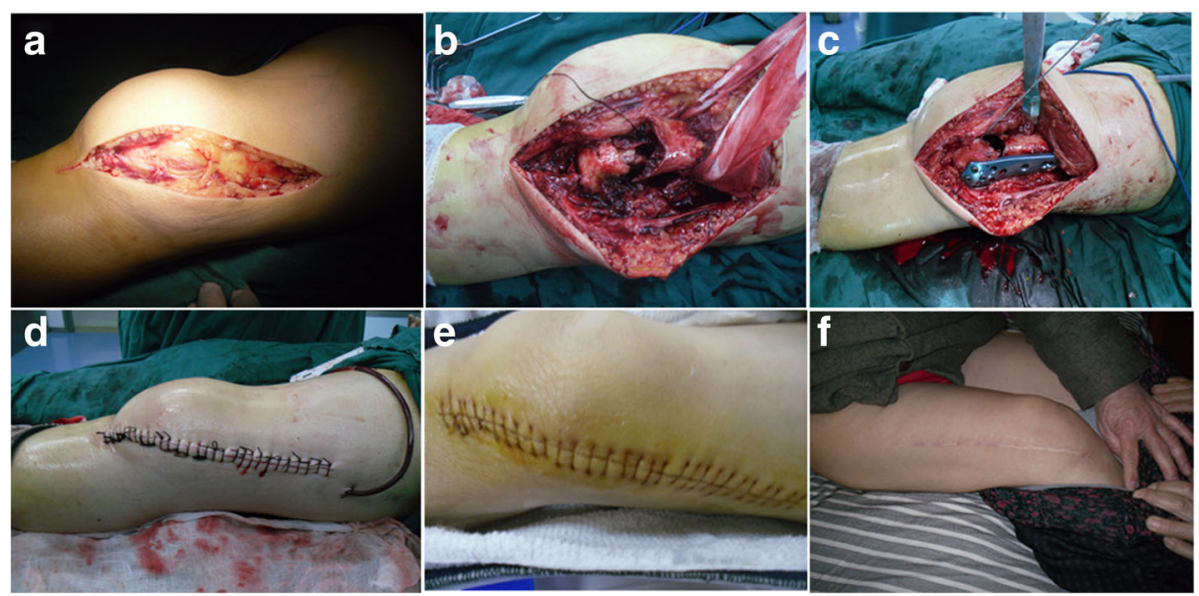

Fig. 2 Surgical procedures and postoperative functional exercise. a The distal femoral incision was extended to the anterolateral part of the knee joint. b The distal femoral fractures was fully revealed and attention should be paid to preserve the integrity of the suprapatellar bursa. c Distal femoral compression locking plate was used for solid fixation. $\mathbf{d}$ The incision was sutured and a drainage tube was placed in the incision. $\mathbf{e}$ The suture was removed according to the wound healing 12 14 days after surgery. f Postoperative functional exercise

a locking compression plate was used for the fixation of the distal femur (Fig. 2c). C-arm X ray fluoroscopy of distal femur joint surface and internal fixation was conducted to check the line of force, the joint surface, position of steel plate, and screw length. The incision was washed with physiological saline and then sewn up. A drainage tube was placed in the incision, and pressure dressing was performed (Fig. 2d).

\section{Postoperative management}

No external fixation was used after the operation. Routine intravenous antibiotic infusion was performed on the patients for 1 day to prevent infection. The balance of water and electrolytes was monitored carefully postoperatively. Routine blood review was performed on patients with much intraoperative bleeding or postoperative drainage fluid. Symptomatic treatment of blood transfusion was conducted in patients with hemoglobin below $8 \mathrm{~g} / \mathrm{L}$. Low-molecular-weight heparin was used to prevent deep venous thrombosis of lower extremities $24 \mathrm{~h}$ after the operation. The drainage tube was removed 48 days after the operation, and the incision was removed and sutured according to the condition of incision healing 12 14 days after the operation (Fig. 2e).

\section{Functional exercise}

The initiative activity of limb ankle and toe and isometric contraction of quadriceps femoris was performed $6 \mathrm{~h}$ after operation (Fig. 2f). Appropriate knee flexion and extension exercise was performed after limb pain relief to promote the secretion of synovial joint capsule and prevent joint stiffness caused by soft tissue contracture. Passive activity should be delayed for patients with unstable comminuted fractures, such as type C3 distal femoral fractures. Pain reliever should be given for patients with poor exercise compliance and fear of pain. The weight-bearing time was adjusted according to the stability of fracture fixation, the general condition of the patients, and the healing situation of the limbs.

\section{Results}

\section{Baseline data}

Nine males and 11 females with a mean age of $44 \pm 3.7$ (22 77) years were included in our study. The causes of injury were vehicular accidents $(n=8)$, falls $(n=11)$, and crush injuries $(n=1)$. According to the AO/OTA classification, the fractures were classified as types $\mathrm{A}_{1}(n=10)$, $\mathrm{A}_{2}(n=7), \mathrm{A}_{3}(n=10), \mathrm{C}_{1}(n=10), \mathrm{C}_{2}(n=10)$, and $\mathrm{C}_{3}$ $(n=14)$. General information of the patients are listed in Table 1.

\section{Postoperative outcomes}

All patients were followed up for an average of 12 months (6 18 months), and all incisions healed by first intention. Nineteen patients had fracture healing (Fig. 3) 3 to 4 months after surgery; 1 case of distal femoral $\mathrm{C}_{3}$ comminuted fracture patient had fracture healing 15 months surgery and received stage II bone grafting and the healing rate of fracture was $95 \%$.

The postoperative joint function was graded according to the Kolmert functional criteria: 14 cases excellent, 4 cases good, 1 case fair, and 1 case poor. All knees reached the state of straightening, and the postoperative excellent rate was $90 \%$. Among them, 8 patients had maximal flexion of more than $120^{\circ}, 10$ patients had flexion between $90^{\circ}$ and $120^{\circ}$, and 2 other patients had flexion of $70^{\circ}$ and $40^{\circ}$. Fixation of the fracture using a locking compression plate through a posterolateral approach seemed 
Table 1 General information of the patients

\begin{tabular}{ll}
\hline Item & \\
\hline Gender (male/female) & $9 / 11$ \\
Mean age (years) & $44 \pm 3.7$ \\
Fracture region (left/right/bilateral) & $10 / 8 / 2$ \\
Injury cause & \\
$\quad$ Vehicular accidents & 8 \\
$\quad$ Fall injuries & 11 \\
Crush injuries & 1 \\
AO/OTA classification $\left(\mathrm{A}_{1} / \mathrm{A}_{2} / \mathrm{A}_{3} / \mathrm{C}_{1} / \mathrm{C}_{2} / \mathrm{C}_{3}\right)$ & $2 / 2 / 6 / 1 / 7 / 2$ \\
Fracture type (open fracture/closed fracture) & $3 / 17$ \\
Complications (multiple injuries/chest injury/ brain injury) & $2 / 1 / 1$ \\
\hline
\end{tabular}

to be an acceptable surgical option for treatment of distal femoral fractures.

\section{Discussion}

High-speed vehicular accidents are responsible for distal femur fractures commonly observed in the young and middle aged. Low energy mechanisms such as fall at home may be responsible for producing fractures of distal femur in the elderly osteoporotic population especially women [2]. Distal femoral fractures are often multifragmentary and/or intra-articular and are subjected to muscular forces that render non-operative treatment a poor option. These factors also place high demands on any surgical implant used to fix these fractures and may lead to failure. Pain, decreased range of motion, and compromised function of the knee joint is a common problem arising out of articular incongruity and improper fixation of articular fragments in such fractures [13]. Distal femur locking plate is still the way forward for treating distal femur fractures. Positive results have been published by researchers with implants such as distal femur nail, dynamic condylar screw, and even addition of a medial plate to a distal femur locking plate for treating distal femur fractures.

At present, the surgical treatment of distal femoral fractures is mainly through the lateral approach and anterolateral approach. However, the internal condyle and articular surface of femur cannot be fully exposed in the lateral approach, so it is difficult to reset the articular cartilage surface accurately. At the same time, the unevenness or fixed infirmness of the residual articular cartilage can lead to traumatic arthritis or dysfunction of the knee joint. The lateral approach may also damage the iliotibial band, resulting in lateral instability of the knee after operation [14-16]. Sher et al. [15] reported that the injury of the tibial tunnel in the lateral approach is likely to result in the instability of the knee joint. In the anterolateral approach, the femoral rectus was separated from the vastus lateralis to reveal the vastus intermedius muscle. The vastus intermedius, periosteum, and the joint capsule were cut longitudinally. To reveal the distal femoral fractures, the rectus femoris, vastus intermedius muscle, and patella were pulled to the medial side. However, it dissected the musculi vastus intermedius, which may result in severe postoperative scar healing and thus greatly affect the contraction of the quadriceps femoris [14]. In the posterolateral approach, the vastus lateralis and the biceps femoris were bluntly separated, and the fracture ends were fully exposed by tractioning the vastus lateralis forward. This operation is simple and time-saving, and the integrity of the vastus lateralis is well protected. This technique avoids the destruction of the local blood flow of the fracture ends caused by the incision of the vastus lateralis muscle. At the same time, this technique can avoid the swelling of the postoperative limb caused by the severe destruction of the local soft tissue. The postoperative pain is lighter, which is conducive to early functional exercise. In this study, the posterolateral approach was used to treat the

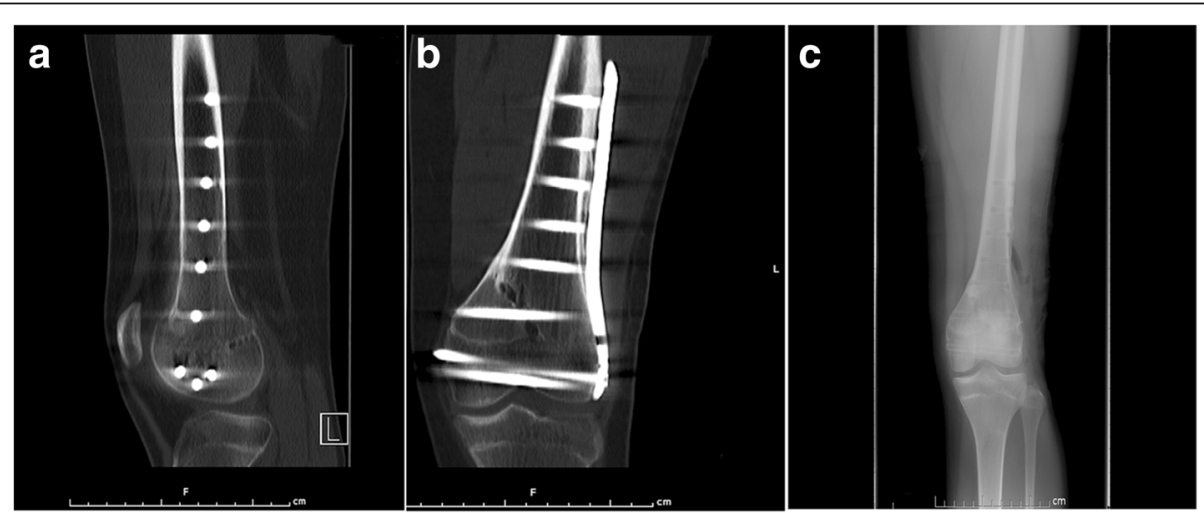

Fig. 3 Six-month postoperative images of CT scans and X-rays. a, b Six-month postoperative CT scans anteroposterior and lateral views showing fracture consolidation. c Six months postoperative X-rays anteroposterior views of knee joint showing fracture consolidation after the removal of internal fixation 
distal femoral fractures, the injury of the vastus intermedius was avoided, and the integrity of the knee extensor device was protected.

While intramedullary nails are well suited to fix extramedullary and simple articular fractures (C1), plates can also be used to treat complex articular fractures. Nevertheless, any displaced articular fracture component must still be anatomically reduced by an open approach and fixed with absolute stability. Fracture fixation was predominantly with anatomical periarticular locking plates, and a smaller number of retrograde intramedullary nails. Whilst this reflects the current literature, with the role of locking plates expanding as the technology evolves [17], studies supporting both methods of fixation have been published [2, 18-23]. Locking compression plates (LCPs), which provide angular stability by minimizing interference with the fracture site, have been used for treatment of distal femoral fractures in osteopenic bone $[24,25]$. In recent years, LCPs have been increasingly used for treating metaphyseal comminuted fractures [26]. In contrast to conventional screw-plate systems that depend on the bone plate interface for stability [27], LCPs have been designed with a fixed-angle construct, enabling placement of the plate without any contact with bone $[25,28-30]$. With associated insertion guides, these plates can be inserted and fixed by minimally invasive techniques, as in the present cases [26]. These characteristics of LCPs facilitate closed reduction of these fractures and preservation of the blood supply at the fracture site. LCPs have improved fixation strength, pull-out strength of locking screws, and purchase in osteoporotic bone $[25,26,28,29]$. Because of these advantages, LCPs were helpful in our patients with distal femoral fractures.

This study has several limitations. Firstly, the retrospective design has its inherent limitations of such study. Another limitation in our study is the short follow-up period and lack of control group. Therefore, a hospitalbased case-control study to compare the clinical outcome between our techniques and the standard method with long-term follow-up is required in future.

\section{Conclusions}

Fixation of the fracture using a locking compression plate through a posterolateral approach seemed to be an acceptable surgical option for treatment of distal femoral fractures.

\section{Abbreviations}

ABP: Angle blade plate; CBP: Condylar buttress plates; DCS: Dynamic condylar screw; IMNs: Intramedullary nails
Funding

No funding was received.

\section{Availability of data and materials}

The datasets used and/or analyzed during the current study are available from the corresponding author on reasonable request.

\section{Authors' contributions}

LS designed the study. WX, WL, and JD performed the experimental work. ZK, LS, and ZZ evaluated the data. WX wrote the manuscript. All authors read and approved the final manuscript.

\section{Ethics approval and consent to participate}

This study was approved by the Third Hospital of Hebei Medical University and followed the Declaration of Helsinki. Informed consent was received from all patients.

\section{Consent for publication}

Not applicable.

\section{Competing interests}

The authors declare that they have no competing interests.

\section{Publisher's Note}

Springer Nature remains neutral with regard to jurisdictional claims in published maps and institutional affiliations.

\section{Author details}

${ }^{1}$ Department of Orthopaedics, The Third Hospital of Hebei Medical University, No. 139 Ziqiang Road, Shijiazhuang 050051, China. ${ }^{2}$ Division of Medical Service, Hebei General Hospital, No. 348 Heping West Road, Shijiazhuang, Hebei 050051, China. ${ }^{3}$ Department of Orthopaedics, Cangzhou People's Hospital, No. 7 Qingchi Avenue, Cangzhou, Hebei 061000, China.

Received: 13 July 2017 Accepted: 2 March 2018

Published online: 16 March 2018

\section{References}

1. Kolmert L, Persson BM, Romanus B. An experimental study of devices for internal fixation of distal femoral fractures. Clin Orthop Relat Res. 1982;40:290-9.

2. Martinet O, Cordey J, Harder Y, Maier A, Buhler M, Barraud GE. The epidemiology of fractures of the distal femur. Injury. 2000;31(Suppl 3):C62-3.

3. Giles JB, DeLee JC, Heckman JD, Keever JE. Supracondylar-intercondylar fractures of the femur treated with a supracondylar plate and lag screw. J Bone Joint Surg Am. 1982;64:864-70.

4. Sanders $\mathrm{R}$, Swiontkowski M, Rosen $\mathrm{H}$, Helfet D. Double-plating of comminuted, unstable fractures of the distal part of the femur. J Bone Joint Surg Am. 1991;73:341-6.

5. Firoozbakhsh K, Behzadi K, DeCoster TA, Moneim MS, Naraghi FF. Mechanics of retrograde nail versus plate fixation for supracondylar femur fractures. J Orthop Trauma. 1995;9:152-7.

6. Helfet $\mathrm{DL}$, Lorich $\mathrm{DG}$. Retrograde intramedullary nailing of supracondylar 342 femoral fractures. ClinOrthop Relat Res. 1998;350:80-4.

7. Krettek C, Schandelmaier P, Miclau T, Bertram R, Holmes W, Tscherne H. Transarticular joint reconstruction and indirect plate osteosynthesis for complex distal supracondylar femoral fractures. Injury. 1997;28(Suppl 1):A31-41.

8. Krettek C, Schandelmaier P, Miclau T, Tscherne H. Minimally invasive percutaneous plate osteosynthesis (MIPPO) using the DCS in proximal and distal femoral fractures. Injury. 1997;28(Suppl 1):A20-30.

9. Hontzsch D. Distal femoral fracture-technical possibilities. Kongressbd Dtsch Ges Chir Kongr. 2001;118:371-4.

10. Reddy J, Chary NB. Functional outcome of distal end of femur with locking compression plate: a prospective study. 2016;

11. Zhang ZM, Liu J, Huang CX, Zhao ZF, Wang G, Qin CC. Treatment of type C3 distal femoral fractures with double-plating fixation via anteriormiddle approach. Zhongguo Gu Shang. 2012;25:1049-52.

12. Zhang B, Dai M, Zou F, Luo S, Li B, Qiu P, Nie T. New anterolateral approach of distal femur for treatment of distal femoral fractures. Zhongguo Xiu Fu Chong Jian Wai Ke Za Zhi. 2013;27:1296-9.

13. Crist BD, Della Rocca GJ, Murtha YM. Treatment of acute distal femur fractures. Orthopedics. 2008;31:681-90. 
14. Kanamiya T, Whiteside LA, Nakamura T, Mihalko WM, Steiger J, Naito M. Ranawat Award paper. Effect of selective lateral ligament release on stability in knee arthroplasty. Clin Orthop Relat Res. 2002;404:24-31.

15. Sher I, Umans H, Downie SA, Tobin K, Arora R, Olson TR. Proximal iliotibial band syndrome: what is it and where is it? Skelet Radiol. 2011;40:1553-6.

16. Whiteside LA. Selective ligament release in total knee arthroplasty of the knee in valgus. Clin Orthop Relat Res. 1999;367:130-40.

17. Ehlinger M, Ducrot G, Adam P, Bonnomet F. Distal femur fractures. Surgical techniques and a review of the literature. Orthop Traumatol Surg Res. 2013; 99:353-60.

18. Acharya KN, Rao MR. Retrograde nailing for distal third femoral shaft fractures: a prospective study. J Orthop Surg (Hong Kong). 2006;14:253-8.

19. Dougherty PJ, Kim DG, Meisterling S, Wybo C, Yeni Y. Biomechanical comparison of bicortical versus unicortical screw placement of proximal tibia locking plates: a cadaveric model. J Orthop Trauma. 2008:22:399-403.

20. Henderson CE, Lujan T, Bottlang M, Fitzpatrick DC, Madey SM, Marsh JL. Stabilization of distal femur fractures with intramedullary nails and locking plates: differences in callus formation. lowa Orthop J. 2010;30:61-8.

21. Kolb W, Guhlmann H, Windisch C, Marx F, Kolb K, Koller H. Fixation of distal femoral fractures with the less invasive stabilization system: a minimally invasive treatment with locked fixed-angle screws. J Trauma. 2008;65:1425-34.

22. Thomson AB, Driver R, Kregor PJ, Obremskey WT. Long-term functional outcomes after intra-articular distal femur fractures: ORIF versus retrograde intramedullary nailing. Orthopedics. 2008;31:748-50.

23. Zlowodzki M, Bhandari M, Marek DJ, Cole PA, Kregor PJ. Operative treatment of acute distal femur fractures: systematic review of 2 comparative studies and 45 case series (1989 to 2005). J Orthop Trauma. 2006;20:366-71.

24. Fulkerson E, Egol KA, Kubiak EN, Liporace F, Kummer FJ, Koval KJ. Fixation of diaphyseal fractures with a segmental defect: a biomechanical comparison of locked and conventional plating techniques. J Trauma. 2006;60:830-5.

25. Stoffel K, Dieter U, Stachowiak G, Gachter A, Kuster MS. Biomechanical testing of the LCP - how can stability in locked internal fixators be controlled? Injury. 2003;34(Suppl 2):B11-9.

26. Ring D, Kloen P, Kadzielski J, Helfet D, Jupiter JB. Locking compression plates for osteoporotic nonunions of the diaphyseal humerus. Clin Orthop Relat Res. 2004:425:50-4.

27. Higgins TF. Distal femoral fractures. J Knee Surg. 2007;20:56-66.

28. Egol KA, Kubiak EN, Fulkerson E, Kummer FJ, Koval KJ. Biomechanics of locked plates and screws. J Orthop Trauma. 2004;18:488-93.

29. Schutz M, Sudkamp NP. Revolution in plate osteosynthesis: new internal fixator systems. J Orthop Sci. 2003;8:252-8

30. Wagner M, Frenk A, Frigg R. New concepts for bone fracture treatment and the locking compression plate. Surg Technol Int. 2004;12:271-7.

\section{Submit your next manuscript to BioMed Central and we will help you at every step:}

- We accept pre-submission inquiries

- Our selector tool helps you to find the most relevant journal

- We provide round the clock customer support

- Convenient online submission

- Thorough peer review

- Inclusion in PubMed and all major indexing services

- Maximum visibility for your research

Submit your manuscript at www.biomedcentral.com/submit

CBiomed Central 